\title{
Giant Gallbladder Revealed by Chronic Cholecystitis Gallstone: A Case Report and Review of the Literature
}

\author{
Houda Mirali ${ }^{1}$, Imane Kamaoui ${ }^{1}$, Tijani El Harroudi ${ }^{2}$, Imane Skiker ${ }^{1}$, Badr Serji ${ }^{2}$ \\ 1. Department of Radiology, Mohammed VI University Hospital, Oujda, MAR 2. Surgical Oncology, Mohammed VI \\ University Hospital, Regional Oncology Center, Oujda, MAR
}

Corresponding author: Houda Mirali, mirali.houda@gmail.com

\begin{abstract}
We report here an extremely rare case of giant gallbladder and discuss diagnostic circumstances and different ethiopathogenic theories. A 53-year-old woman presented acute right hypochondrium pain. Ultrasonography showed a huge cystic mass with gallstones and a CT scan confirmed the diagnosis of giant gallbladder. Cholecystectomy was performed. Outcomes were uneventful and histopathological examination of the specimen confirmed the presence of chronic cholecystitis.
\end{abstract}

Enlargement of the gallbladder is related to biliary retention. This enlargement is favored by the slow evolution of malignant pathologies. However, some benign situations have been reported in the literature, and giant gallbladder can occur in a benign situation even if its ethiopathogeny is not so clear.

Categories: Radiology, General Surgery

Keywords: giant, gallbladder, chronic obstruction, gallstone cholecystitis

\section{Introduction}

Enlarged gallbladders in adults are usually observed with malignancies, especially in association with pancreatic or distal biliary tumor [1]. In benign situations, they are very rare. We report a case of giant gallbladder.

Review began 02/13/2021 Review ended 03/15/2021 Published 03/15/2021

() Copyright 2021 Mirali et al. This is an open access article distributed under the terms of the Creative Commons Attribution License CC-BY 4.0., which permits unrestricted use, distribution, and reproduction in any medium, provided the original author and source are credited.

\section{Case Presentation}

A 53-year-old woman, who had no medical history in relation to the gallbladder disease, admitted to the emergency department due to acute abdominal pain in the right hypochondrium without vomiting, fever, or jaundice. Over the past year, she had often suffered from abdominal pain, which she attributed to a colonic disorder. At admission, physical examination revealed a large, sensitive abdominal mass in the right hypochondrium that extended to the upper part of the right iliac fossa. Her body temperature was $37.1^{\circ} \mathrm{C}$, pulse $81 / \mathrm{min}$, and blood pressure 130/70 $\mathrm{mmHg}$. Ultrasonography showed a large, well-delineated cystic mass with a wall thickness of $9 \mathrm{~mm}$ that contained multiple large gallstones. Imaging of the common bile duct was difficult because the intrahepatic biliary tract was not dilated, and an enlarged gallbladder was suspected. Abdominal computed tomography (CT) confirmed the diagnosis of enlarged gallbladder with massive hydrops and showed multiple gallstones with a large one at the neck of the gallbladder (Figure 1). The distal part of the common bile duct was not dilated, but the proximal part was dilated, although no intracholedochal gallstone was visible. Laboratory tests demonstrated a white blood cell count of $6600 / \mathrm{mm} 3$, C-reactive protein level of $15.47 \mathrm{mg} / \mathrm{dL}$, a total bilirubin level of $=6.70 \mu \mathrm{mol} / \mathrm{L}$, a gamma glutamyl transferase level of $25 \mathrm{IU} / \mathrm{L}$, an alkaline phosphatase level of $64 \mathrm{UI} / \mathrm{L}$, a prothrombin level of $93 \%$, and a lipase level of $14 \mathrm{UI} / \mathrm{L}$. The diagnosis of painful gallbladder with hydrocholecystitis was thus retained. Surgical exploration through a right subcostal incision confirmed the diagnosis. Dissection in the triangle of Callot showed that the gallbladder was exerting a mass effect on the common bile duct, which explained the proximal dilatation shown on CT (Figure 2). After the dissection of the cystic pedicle, cholecystectomy was performed. A drainage system was left for two days after surgery. The postsurgical course was uneventful, and the patient was discharged three days after the surgery. Histopathologic study confirmed the diagnosis of giant chronic cholecystitis, in which the gallbladder measured $22 \times 14$ × $10 \mathrm{~cm}$ without malignancy (Figure 3). 


\section{Cureus}

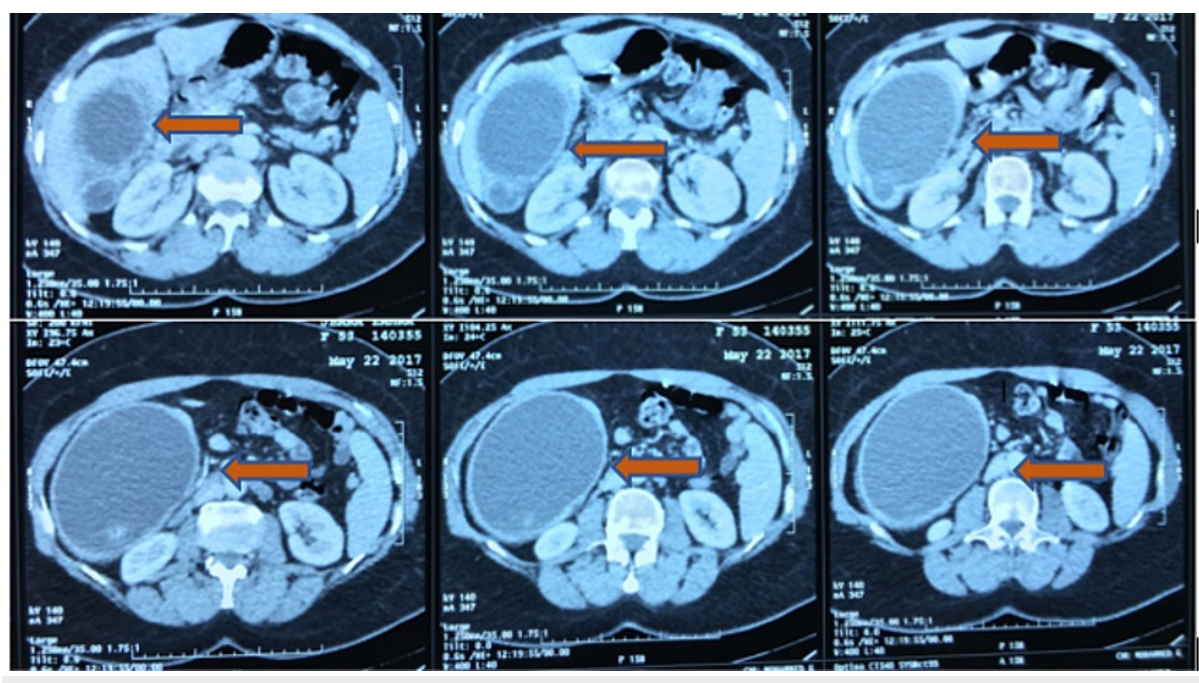

FIGURE 1: CT imaging showing a huge gallbladder with wall thickening

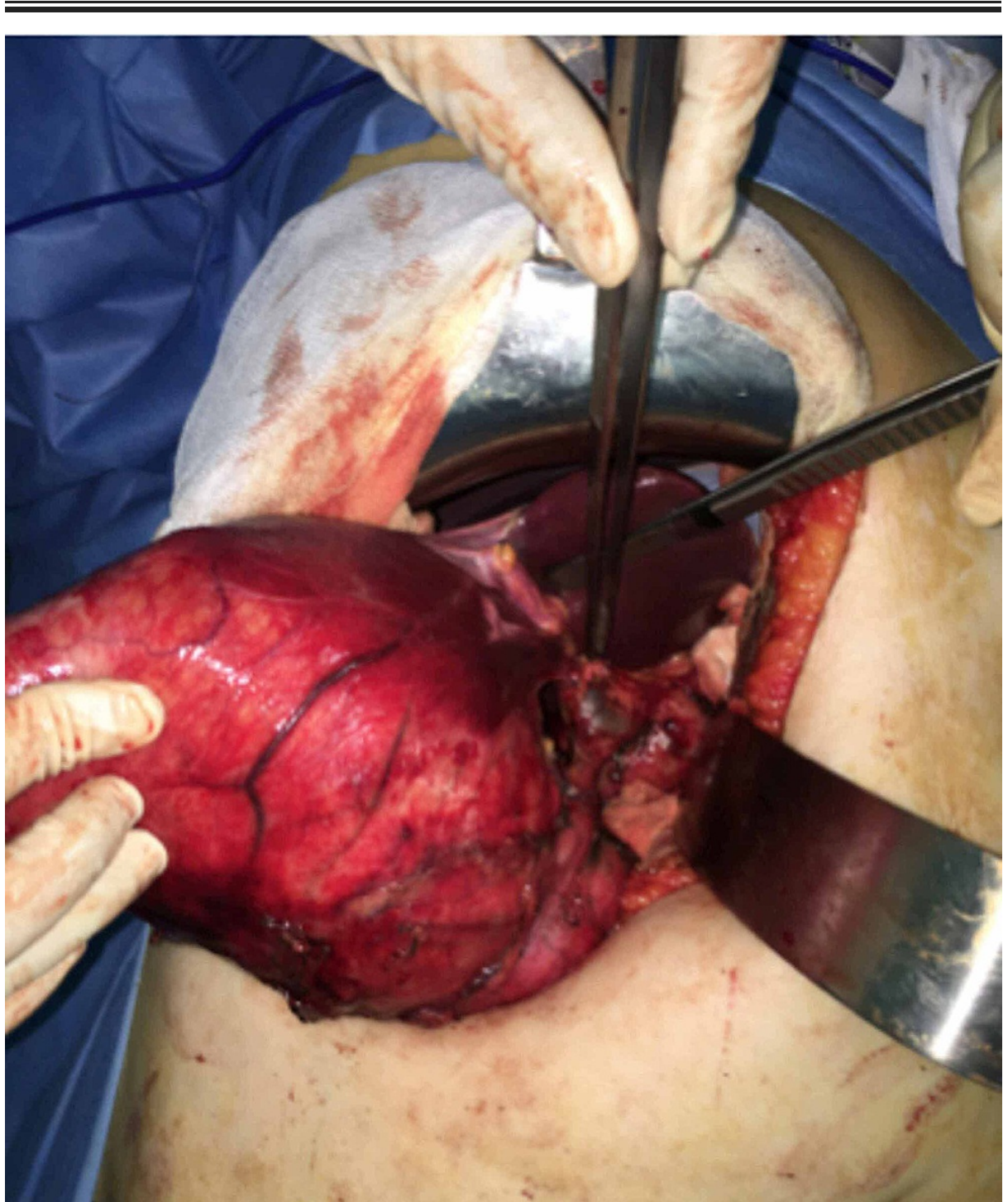

FIGURE 2: Per operative view 


\section{Cureus}

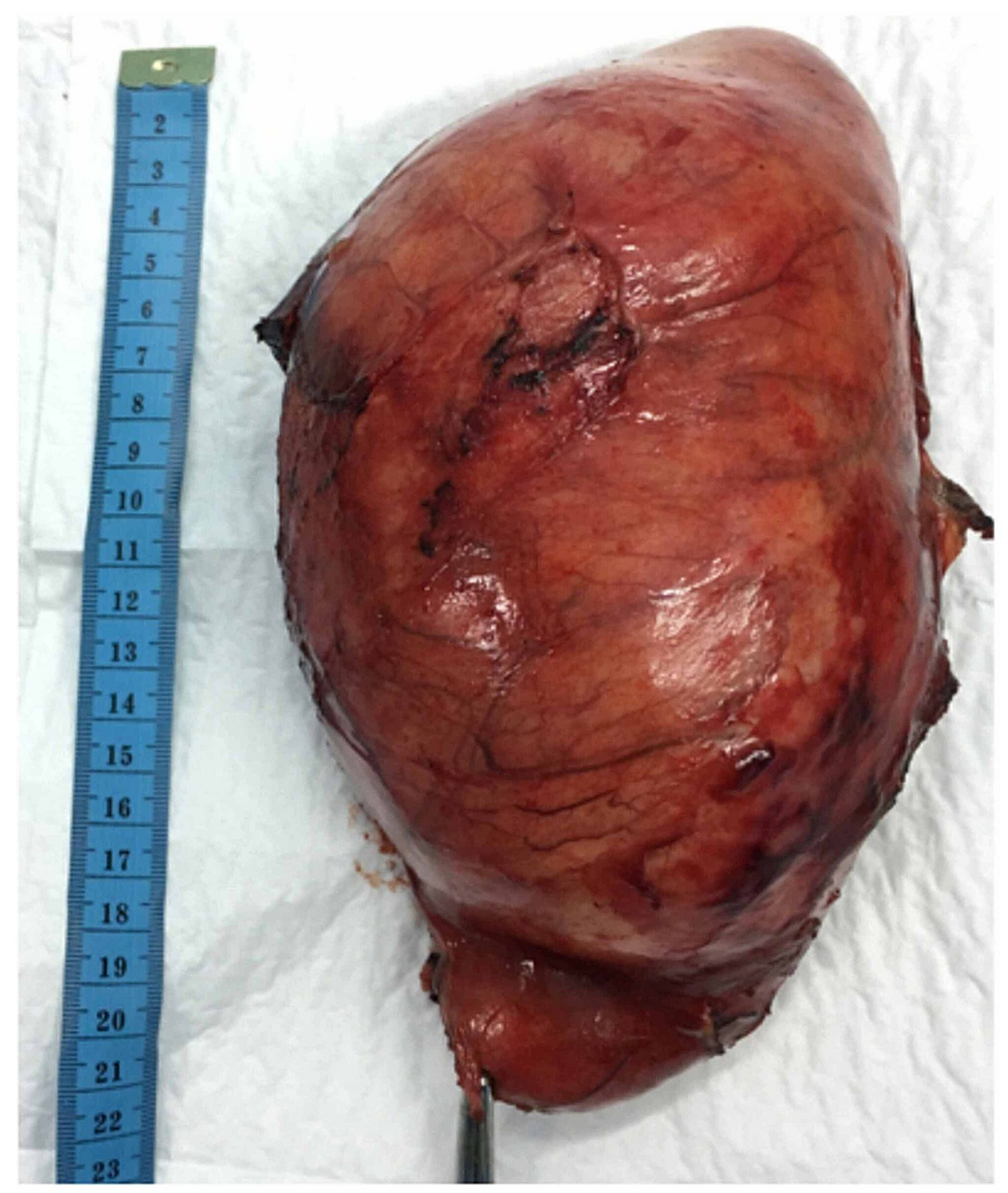

FIGURE 3: Operative part after resection

\section{Discussion}

The diagnosis of giant gallbladder may be difficult, especially in children, and can be confused with other abdominal cystic masses or with giant choledochal cyst [2,3]. In adults, enlargement of the gallbladder is usually related to biliary retention. According to Courvoisier's law, the progressive growth of malignancy (such as a tumor in the pancreatic head or distal biliary tumor) allows the enlargement of the gallbladder over time [4]. By the same physiopathologic process, gallbladder malignancy that obstructs the cystic duct can, in very rare cases, lead to the same situation [5]. However, in very few cases reported in the literature, the presence of a hepatic disorder such as Byler's disease or congenital large gallbladder was associated with the presence of a large gallbladder in adults without any obstructive causes [6-8]. In our patient, the enlargement of the gallbladder was associated with large gallstones. CT showed a large one localized at the neck of the gallbladder. Those stones may be mobile and may cause intermittent obstruction of the biliary cystic duct, which can lead to chronic cholecystitis, progressive enlargement of the gallbladder, and massive hydrocholecystitis. This mechanism may explain the few cases of big gallbladder with cholelithiasis reported in the literature [8-10].

Table 1 lists the few cases reported in PubMed in the English literature. The majority of cases have been in women aged $>50$ years old and the reports have emphasized the length of time over which the gallbladder was enlarged. 


\section{Cureus}

\begin{tabular}{|c|c|c|c|c|c|c|}
\hline Publication & Age & Sex & Diagnosis conditions & Size (mm) & Stones & Pathologist findings \\
\hline Grosberg (1962) [9] & 95 & $\mathrm{~F}$ & Emergency & 140 & Yes & Gangrenous cholecystitis \\
\hline Maeda et al. (1979) [8] & 36 & $\mathrm{~F}$ & Abdominal Mass & 180 & No & Normal gallbladder \\
\hline Hsu et al. (2011) [5] & $8 \gamma$ & $\mathrm{r}$ & Emergency & 164 & Yes & Adenocarcinoma \\
\hline Panaro et al. (2012) [6] & 17 & $M$ & Byler's disease & 430 & No & Normal gallbladder \\
\hline Zong et al. (2013) [7] & 55 & $\mathrm{~F}$ & Abdominal mass & 300 & No & Inflammatory cell infiltration \\
\hline Kuznetsov et al. (2014) [10] & 77 & $\mathrm{~F}$ & Emergency & 240 & Yes & Chronic cholecystitis \\
\hline Mirali et al. (present study) & 53 & $\mathrm{~F}$ & Emergency & 220 & Yes & Chronic cholecystitis \\
\hline
\end{tabular}

TABLE 1: Cases of giant gallbladder reported in PubMed

\section{Conclusions}

Giant gallbladder can be one of the atypical presentations of benign biliary tract diseases. We discuss the case of a female patient with chronic hypochondrium pain. Imaging results by ultrasonography and computed tomography showed a huge gallbladder with wall thickness that contained multiple large gallstones; in addition, neither biliary duct dilatation nor tumor in the pancreatic head was demonstrated. This case report may highlight the infrequent benign situations associated with enlargement of the gallbladder.

\section{Additional Information}

\section{Disclosures}

Human subjects: Consent was obtained or waived by all participants in this study. Conflicts of interest: In compliance with the ICMJE uniform disclosure form, all authors declare the following: Payment/services info: All authors have declared that no financial support was received from any organization for the submitted work. Financial relationships: All authors have declared that they have no financial relationships at present or within the previous three years with any organizations that might have an interest in the submitted work. Other relationships: All authors have declared that there are no other relationships or activities that could appear to have influenced the submitted work.

\section{References}

1. Verghese A, Berk SL: Courvoisier's law. Lancet. 1986, 327:99. 10.1016/s0140-6736(86)90749-X

2. Wootton-Gorges SL, Thomas KB, Harned RK, Wu SR, Stein-Wexler R, Strain JD: Giant cystic abdominal masses in children. Pediatr Radiol. 2005, 35:1277-88. 10.1007/s00247-005-1559-7

3. Choi JI, Lall C, Bhargava P, Imagawa DK: Giant choledochal cyst mimicking massive gallbladder hydrops in an adult patient: multi detector computed tomography and magnetic resonance imaging findings correlated to gross and histopathological findings. J Clin Imaging Sci. 2013, 29:45. 10.4103/2156-7514.120785

4. Watts GT: Courvoisier's law. Lancet. 1985, 326:1293-1294. 10.1016/s0140-6736(85)91568-5

5. Hsu KF, Yeh CL, Shih ML, Hsieh CB, Hsu HM: Giant gallbladder: adenocarcinoma complicated with empyema. J Trauma. 2011, 70:261. 10.1097/TA.0b013e31818c29fd

6. Panaro F, Chastaing L, Navarro F: Hepatobiliary and pancreatic: giant gallbladder associated with Byler's disease. J Gastroenterol Hepatol. 2012, $27: 620$. 10.1111/j.1440-1746.2012.07058.x

7. Zong L, Chen P, Wang L, He C, Wang G, Jiang J, Wang H: A case of congenital giant gallbladder with massive hydrops mimicking celiac cyst. Oncol Lett. 2013, 5:226-228. 10.3892/ol.2012.1010

8. Maeda Y, Setoguchi T, Yoshida T, Katsuki T: A giant gallbladder. Gastroenterol Jpn. 1979, 14:621-4. 10.1007/BF02773722

9. Grosberg SJ: Giant gallbladder. Am J Dig Dis. 1962, 7:1039-40. 10.1007/BF02231907

10. Kuznetsov AV, Borodach AV, Fedin EN, Khromova AD: Giant gallbladder: a case report and review of literature. Int J Surg Case Rep. 2014, 5:673-6. 10.1016/j.ijscr.2014.08.005 